\title{
ESTRUTURA CONTÁBIL DAS MICROEMPRESAS: UM ESTUDO NO BAIRRO GRAJAÚ-SP
}

\author{
STRUCTURE OF ACCOUNTING MICRO: CASE STUDY IN GRAJAÚ-SP
}

Recebido: 02/10/2017 - Aprovado: 22/11/2017 - Publicado: 30/12/2017 Processo de Avaliação: Double Blind Review

\author{
Raul Gomes Pinheiro ${ }^{1}$ \\ Doutor em Administração e Mestre em Ciências Contábeis \\ Professor da Fundação Escola de Comércio Álvares Penteado (FECAP) \\ raulpinheiro@hotmail.com \\ Soraya Costa Silva \\ Especialista em Gestão Tributária \\ Fundação Escola de Comércio Álvares Penteado (FECAP) \\ sosilva@biolabfarma.com.br \\ Marcus Vinicius Moreira Zittei \\ Doutor em Ciências Contábeis e Administração \\ Professor da Fundação Escola de Comércio Álvares Penteado (FECAP) \\ marcuszittei@zittei.com.br

\section{Leonardo Fabris Lugoboni} \\ Doutor e Mestre em administração, professor \\ Professor da Fundação Escola de Comércio Álvares Penteado (FECAP) \\ leo_fabris@hotmail.com
}

RESUMO: Este estudo tem o objetivo de identificar a estrutura contábil entre as microempresas localizadas no bairro do Grajaú no município de São Paulo - SP. A pesquisa foi aplicada em 30 MPEs de setores diversificados, a maioria atuando há 3 e 4 anos no mercado. Os resultados demonstraram que todas as MPEs pertencem ao regime de tributação do SIMPLES e realizam sua contabilidade em escritórios especializados. Verificou-se que a maioria das empresas possui de 1 a 3 funcionários. Concluiu-se que, as empresas com faturamento de até R \$ 30.000,00 não possuem o conhecimento sobre contabilidade gerencial, e, consequentemente, não fazem uso dessa ferramenta de gestão.

\footnotetext{
${ }^{1}$ Autor para correspondência: Fundação Escola de Comércio Álvares Penteado, Largo São Francisco, 19 - Sé, São Paulo SP, Brasil, 01003-000
} 
Palavras-chave: micro e pequenas empresas; Contabilidade; Contabilidade Gerencial; Competitividade; estrutura contábil.

ABSTRACT: This study aimed to identify the accounting structure among microenterprises located in Grajaú neighborhood in São Paulo - SP. The poll was conducted in 30 MSBs of diversified sectors, most operating for 3 and 4 years in the market. The results showed that all MEPs belong to the SIMPLE taxation system and carry out their accounting in specialized offices. It was found that most companies have 1 to 3 employees. It was concluded that companies with revenues of up to $R \$ 30,000.00$ have no acquaintance of management accounting, and hence do not use this management tool.

Keywords: micro and small enterprises; Accounting; Management Accounting; Competitiveness; Accounting structure.

\section{INTRODUÇÃO}

Atualmente, a informação é um dos produtos mais valiosos para a gestão das organizações, proporcionando oportunidades de negócios e identificando ameaças, tornandose vital para os gestores e para a sobrevivência das micro e pequenas empresas (SEBRAE, 2012). Neste contexto, Andrade (2012 p. 8) pontua que "as Micro e Pequenas Empresas (MPEs) funcionam como vetores da distribuição de renda e possibilitam oportunidades de trabalho a milhões de pessoas".

No Brasil existem 6,3 milhões de empresas. Desse total, 99\% são micro e pequenas empresas (MPEs). Os pequenos negócios respondem por mais de dois terços das ocupações do setor privado. Assim, verifica-se o potencial de empreendedorismo no país e o papel importante desempenhado pelas MPEs (SEBRAE, 2012). Cerca de 1,6 milhão de MPEs paulistas, o equivalente a $80 \%$ do total de empreendimentos de pequeno porte de todo o estado de São Paulo, contam com algum tipo de tratamento diferenciado para abertura, fortalecimento ou consolidação de suas atividades de acordo com as vantagens oferecidas pelos municípios onde estão situadas (CAETANO et al., 2012).

A cada cem empresas criadas no Brasil, quase 76 sobrevivem aos dois primeiros anos de vida (75,6\%). De cada 100 empresas abertas em São Paulo, 77 rompem a barreira dos dois 
anos, o equivalente a uma taxa de mortalidade de $23 \%$ no estado (SEBRAE, 2013). Um dos pontos essenciais para a sobrevivência das Micro e Pequenas Empresas (MPEs) é sua estrutura contábil, sua contabilidade financeira e gerencial que é basicamente composta pelo fluxo de caixa, controle de estoque, orçamento, controle de contas a pagar e receber (SOUZA e RIOS, 2011).

Identificar a estrutura contábil entre as microempresas localizadas no bairro do Grajaú no município de São Paulo - SP

- Compreender a importância da estrutura contábil para microempresas;

- Relacionar a estrutura contábil com a permanência das microempresas no mercado competitivo;

- Relatar a importância da gestão da informação no controle financeiro.

De acordo com Caetano et al. (2012), não basta ter grandes números de crescimento somente em quantidade, mas incentivar e qualificar os empreendimentos de pequeno porte junto com os Microempreendedores, incentivando-os na melhoria do ambiente de negócio, e enfatizar a importância do profissional e da estrutura contábil nas empresas de baixo porte.

O profissional contábil não pode se limitar somente a essas obrigações entre empresa e governo, mas sim mostrar-se capaz realizando, além das obrigações físcais, uma consultoria diretamente ligada aos administradores da empresa (AUTRAN e COELHO, 2012).

Diante disso, este estudo justifica-se na medida em que, ao conhecer as estruturas contábeis das MEs do bairro do Grajaú, torna-se possível a intervenção dos profissionais contábeis frente às necessidades identificadas, e, consequentemente, aumentando o tempo de sobrevivência das MEs e sua capacidade de enfrentamento das concorrências acirradas de um mercado globalizado.

Uma estrutura contábil eficiente e a atuação do profissional contábil nas MPEs podem contribuir para sua permanência no mercado competitivo?

\section{REFERENCIAL TEÓRICO}

\subsection{CONTEXTUALIZAÇÃO DAS MICRO E PEQUENAS EMPRESAS NO BRASIL}

De acordo com a Lei Complementar n. 123/2006, existem várias formas de organizações, entre elas as micros e pequenas empresas que são classificadas de acordo com o Estatuto Nacional da Micro Empresa e da Empresa de Pequeno Porte (BRASIL, 2006). 
A Tabela 1 demonstra os critérios utilizados para a classificação das MPEs de acordo com o número de empregados e do faturamento anual:

Tabela 1 - Critérios de classificação das MPEs

\begin{tabular}{l|l|l}
\hline \multicolumn{1}{c|}{ Porte da Empresa } & Número de Empregados & Faturamento Lei 123/06 \\
\hline Microempresa & $\begin{array}{l}\text { Indústria: até 19 } \\
\text { empregados. } \\
\text { Comércio e Serviços: até 9 } \\
\text { empregados. }\end{array}$ & $\begin{array}{l}\text { Microempresa - ME - Até } \\
\text { R \$ 360.000,00 }\end{array}$ \\
\hline Empresas Pequeno Porte & $\begin{array}{l}\text { Indústria: de 20 a 99 } \\
\text { empregados. } \\
\text { Comércio e Serviços: de } \\
10 \text { a 49 empregados. }\end{array}$ & $\begin{array}{l}\text { Empresa de Pequeno Porte } \\
\text { até R } \$ 3.600 .000,00\end{array}$ \\
\hline
\end{tabular}

Fonte: SEBRAE, 2013.

Conforme apresentado na Tabela 1, as indústrias com até 19 empregados, o setor de comércio e serviços que contam com até 9 empregados e possuem um faturamento anual de até $\mathrm{R} \$ 360.000,00$ são classificados como microempresas. Enquanto que, para ser classificada como Empresa de pequeno porte, a indústria precisa ter de 20 a 99 colaboradores e o setor de comércio e serviços de 10 a 49 colaboradores. Necessita ainda ter um faturamento anual compreendido entre $\mathrm{R} \$ 360.000,00$ até $\mathrm{R} \$ 3.600 .000,00$ para ser enquadrada como uma empresa de pequeno porte (SEBRAE, 2013).

As MPEs estão distribuídas pelo país da seguinte forma: $52 \%$ atuam no comércio; $33 \%$ em serviços e $15 \%$ na indústria. São responsáveis por 52\% dos empregos formais e $40 \%$ da massa salarial, influenciando de forma direta na geração de recursos que representa $25 \%$ do Produto Interno Bruto- PIB nacional (AZEVEDO, 2013).

Segundo Barretto (2013) esse crescimento tem ligação direta com a flexibilização da legislação, como a criação no ano de 2007 do Simples Nacional, um regime tributário diferenciado, aplicável aos micros e pequenos empreendedores.

\footnotetext{
A criação da Lei Geral da Micro e Pequena Empresa em 2006 conseguiu melhorar muito o ambiente legal para os pequenos negócios. Entre os benefícios está a criação do Simples, que reduz em média $40 \%$ a carga tributária para pequenos negócios e unifica oito impostos em um único boleto (BARRETO, 2013 p.2).
}

A criação da Lei Geral da Micro e Pequena Empresa em 2006 proporcionou ganhos nas questões legais para os pequenos negócios. Entre os benefícios está a criação do Simples, 
que reduz em média $40 \%$ a carga tributária para pequenos negócios e unifica oito impostos em um único boleto (SEBRAE, 2013).

A Lei Complementar 123/2006 (também chamada de Lei Geral) é de suma importância no processo de criação de vantagem competitiva para as MPEs. Trata-se do novo Estatuto Nacional das Microempresas e das Empresas de Pequeno Porte que estabelecer normas gerais relativas ao tratamento diferenciado e favorecido a ser dispensado às Microempresas (ME) e às Empresas de Pequeno Porte (EPP) no âmbito dos poderes da União, dos estados, do Distrito Federal e dos Municípios, nos termos dos artigos 146, 170 e 179 da Constituição Federal.

Entre os diversos benefícios da Lei Geral para as MPEs, destaca-se a viabilização de maior participação nas compras públicas, como a exclusividade nos contratos que envolvam até R\$ 80 mil e o maior prazo para a apresentação dos documentos exigidos. A Lei Geral e a criação do pregão eletrônico contribuem significativamente para descomplicar os processos e facilitar a participação das MPEs nas licitações públicas (SEBRAE, 2016).

As MPEs enfrentam grandes desafios para sobreviverem aos dois primeiros anos diante das inúmeras pressões externas e internas do mercado. Neste contexto, Lee et al. (2010) apontam os principais problemas enfrentados por elas em sua atuação no ambiente de negócios, conforme Tabela 2:

Tabela 2 - Principais dificuldades enfrentadas pelas MPEs no mercado

\begin{tabular}{|c|c|}
\hline Fatores & Descrição \\
\hline $\begin{array}{l}\text { Relacionados ao } \\
\text { ambiente interno } \\
\text { da empresa }\end{array}$ & $\begin{array}{l}\text { - Falta de pessoal interno com as competências necessárias ao } \\
\text { negócio; } \\
\text { - Inovação tecnológica por imitação, que, quando se torna a única } \\
\text { forma de inovar, pode coibir a iniciativa de criar; } \\
\text { - Baixa capacidade de gestão de pesquisa e desenvolvimento } \\
\text { (P\&D); } \\
\text { - Falta de informação tecnológica; } \\
\text { - Dificuldades em arcar com os custos de comercialização dos } \\
\text { produtos relativos à inovação; } \\
\text { - Pouco conhecimento de mercado. }\end{array}$ \\
\hline $\begin{array}{c}\text { Relacionados ao } \\
\text { ambiente externo } \\
\text { da empresa }\end{array}$ & $\begin{array}{l}\text { - Dificuldade em encontrar mão de obra qualificada; } \\
\text { - Incerteza de mercado quanto à criação de produtos inovadores; } \\
\text { - Dificuldades na obtenção de créditos em virtude do elevado risco } \\
\text { de incerteza tecnológica; } \\
\text { - Competição em mercados monopolistas ou oligopolistas. }\end{array}$ \\
\hline
\end{tabular}

Fonte: Adaptado de Lee et al., 2010 
Entre fatores relacionados ao ambiente interno da empresa têm-se elementos que interferem e impactam de forma significativa no desempenho da empresa, como apontado na Tabela 2.

Verifica-se que as questões tecnológicas demandam investimentos em capacitação profissional, visando o entendimento e aplicabilidade das novas tecnologias, inclusive para o controle das finanças por meio de softwares especializados.

Relacionados ao ambiente externo as empresas tem a competitividade no mercado globalizado e as dificuldades inerentes à falta de mão de obra qualificada para suprir às demandas existentes por um determinado setor (LUCAS, 2013). Com o aumento da competitividade, as empresas precisam ser cada vez mais inovadoras e criativas, não apenas em termos de produzir melhor e mais barato, como também em termos de marketing e finanças, ou seja, sempre em busca por maior competitividade (LEE et al., 2010).

Além dessas dificuldades internas e externas, a falta de uma estrutura contábil, que tem como objetivo fornecer instrumentos aos gestores voltados à melhor utilização dos recursos econômicos da empresa pode comprometer o sucesso da organização (ALMEIDA, 2013).

As MPEs devem estar preparadas para tais transformações. Visando auxiliar as MPEs, a Fundação Nacional da Qualidade (FNQ) publicou o Modelo de Excelência da Gestão (MEG), baseado nos fundamentos e critérios de excelência, proporcionando às organizações a autoavaliação, melhoria no clima organizacional, aumento da competitividade e elevação do desempenho financeiro, além de estabelecer uma sistemática eficiente de gestão dos clientes da empresa (FNQ, 2014).

Atualmente, diante de cenários de incertezas globais e constantes transformações, uma pesquisa realizada pela Omni Marketing em 2013 no Brasil apontou cinco forças globais de transformações que poderão significar oportunidades para MPEs ou grandes desafios (MARTINS, 2013):

1) O crescimento de mercados emergentes;

2) As alterações demográficas, a sociedade e a produtividade do trabalho;

3) O fluxo global de produtos, informações e capital;

4) As mudanças climáticas e a sustentabilidade e

REMIPE- Revista de Micro e Pequenas Empresas e Empreendedorismo da Fatec Osasco 
5) $\mathrm{O}$ crescimento do papel dos governos nas economias e na sustentabilidade ambiental e social.

Em suma, o Modelo de Excelência da Gestão trata-se de uma ferramenta de gestão que estimula a organização a ficar atenta às necessidades e expectativas das diversas partes interessadas, utilizando essas informações para formular o seu planejamento estratégico e desdobramentos (FNQ, 2014).

O Modelo de Excelência da Gestão (MEG) está dividido em oito critérios, conforme observa-se na Figura 1:

Figura 1 - Critérios do Modelo de Excelência de Gestão (MEG)

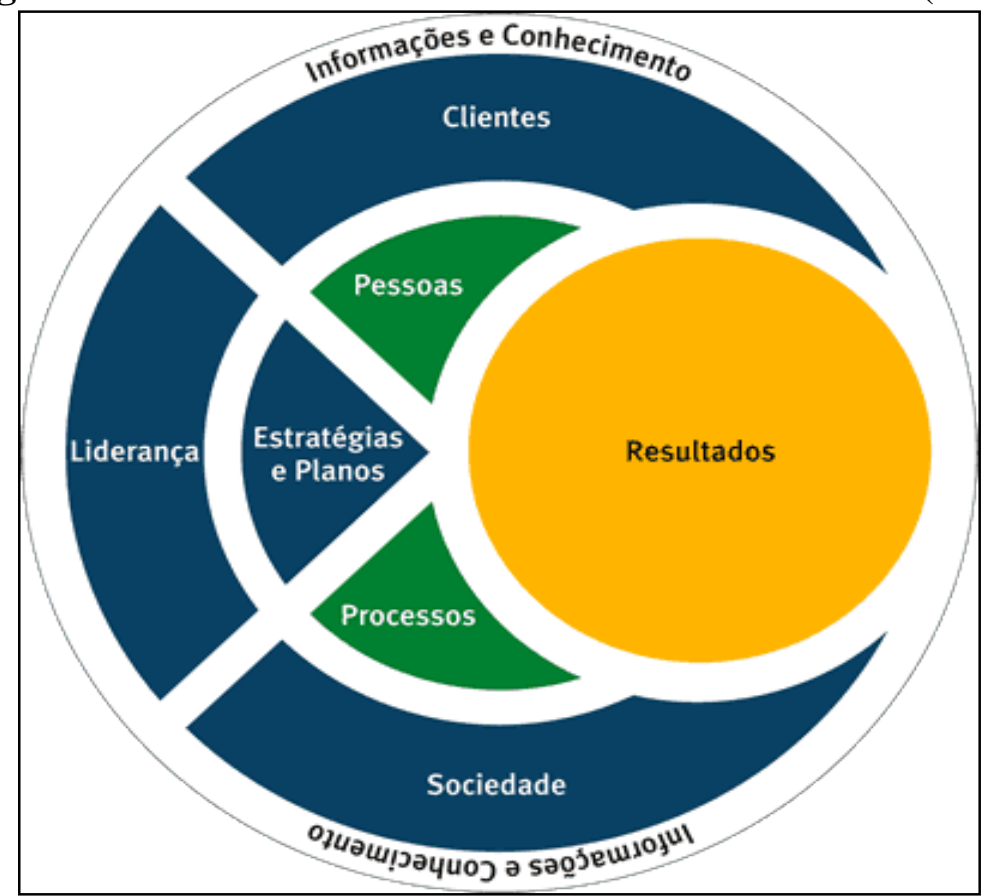

Fonte: FNQ, 2013.

A implementação desses critérios (Liderança, Estratégias e Planos, Clientes, Sociedade, Informações e Conhecimento, Pessoas, Processos e Resultados), permite que as MPEs tenham uma visão sistêmica da sua gestão, e, consequentemente, possam identificar prioridades e dificuldades, funcionando como uma forma de prevenção às incertezas do mercado global (MARTINS, 2013). Pode-se verificar na Figura 1 que entre os principais desafios para as MPEs configura-se o desenvolvimento sustentável, ou seja, a eficiência econômica com a preservação dos recursos naturais e com justiça social.

O contexto desenvolvimento sustentável entre as MPEs também é considerado fator estratégico de sobrevivência das empresas, podendo afirmar que o progresso e o sucesso de 
uma organização não estão somente atrelados ao desempenho financeiro, mas na criação de um valor social e ambiental (SILVA et al. 2015).

\title{
1.2. ESTRUTURA CONTÁBIL
}

De acordo com Iudícibus (2010 p.5), a contabilidade pode ser compreendida como "um método de identificar, mensurar e comunicar informação econômica, financeira, física e social, a fim de permitir decisões e julgamentos adequados por parte dos usuários da informação". Algumas informações da contabilidade são mais interpretativas e relevantes, pois relatam a situação real da empresa, como as utilizadas na contabilidade gerencial (CHING, 2010).

Segundo Iudícibus, (2010, p.21):

\begin{abstract}
A contabilidade gerencial pode ser caracterizada, superficialmente, como um enfoque especial conferido a várias técnicas e procedimentos contábeis já conhecidos e tratados na contabilidade financeira, na contabilidade de custos, na análise financeira e de balanços etc., colocados numa perspectiva diferente, num grau de detalhe mais analítico ou numa forma de apresentação e classificação diferenciada, de maneira a auxiliar os gerentes das entidades em seu processo decisório.
\end{abstract}

A contabilidade gerencial dispõe de ferramentas que contribuem para avaliar o desempenho de uma empresa, auxiliando no processo de planejamento e decisão. Entre elas destacam-se:

- Controle de Contas a Pagar: é o controle de toda conta de financiamento em curto e longo prazo adquirida por serviços recebidos e que ainda precisam ser quitados (IUDÍCIBUS, 2010).

- Controle de Contas a Receber: possibilita ao gestor analisar pontos importantes como: o montante dos valores a receber, programar as receitas, visualizar as constas vencidas e a vencer, identificar os clientes que não pagam em dia, programar despesas e investimentos (CONCEIÇÃO E SOUZA, 2013).

- Controle de Estoque: gerir um estoque exige responsabilidade no planejamento, previsão, controle da formação e manutenção, devendo-se utilizar de ferramentas, como a Curva ABC, para auxiliar esse controle (IUDÍCIBUS, 2010). 
- Orçamento: pode ser utilizado nos ajustes de processos de acordo com o orçamento apresentado, identificando possíveis gargalos e pontos considerados críticos na empresa, criando a possibilidade de minimizar ou eliminar seus efeitos (CONCEIÇÃO E SOUZA, 2013).

- Fluxo de Caixa: reúne informações fundamentais para estabelecer tarefas cotidianas que interferem no processo de tomada de decisão, realização dos investimentos, aquisição de ativos, estoques, contratação de recursos humanos, entradas de caixa, entre outros (SEBRAE, 2016).

\section{METODOLOGIA}

Inicialmente, para a realização deste estudo utilizou-se como metodologia a pesquisa bibliográfica, que segundo Gil (2012) é aquela desenvolvida a partir de material já elaborado, constituído principalmente de livros e artigos científicos.

Posteriormente, realizou-se um estudo de campo por meio de um questionário, sobre a importância de uma estrutura contábil nas microempresas. A pesquisa foi realizada em entre as microempresas de diversos ramos de atividades, localizadas no bairro Grajaú no município de São Paulo Capital.

Esta pesquisa foi realizada no mês de setembro de 2016. O instrumento de coleta de dados utilizado na pesquisa qualitativa foi o questionário. Gil (2012) afirma que o questionário é um documento contendo uma série ordenada de perguntas que devem ser respondidas pelos sujeitos, podendo ser com ou sem a presença do pesquisador. Foram incluídas na pesquisa as microempresas com mais de um ano de funcionamento no bairro. Serão excluídas as microempresas abertas há menos de 12 meses.

As perguntas de um questionário podem ser abertas ou fechadas. Entende-se por perguntas abertas aquelas nas quais o respondente pode escrever livremente dentro do espaço pautado, enquanto que, as perguntas fechadas oferecem algumas opções restritas de respostas possíveis (GIL, 2012). Utilizou-se um questionário semiestruturado contendo 9 questões do tipo fechadas e 1 do tipo aberta. Após a coleta, os dados foram digitados no software Microsoft Excel for Windows $8 \circledR$ para obter o cálculo estatístico. Os dados são apresentados na forma de tabelas e gráficos para análise e discussão 


\section{ANÁLISE E DISCUSSÃO DOS RESULTADOS}

A pesquisa foi aplicada em 30 MPEs de setores diversificados, sendo 33,33\% ( $n=10)$ setor de alimentação, 16,67\% ( $\mathrm{n}=5)$ higiene e beleza, 13,34\% (n=4) comércio de armarinhos, entre outros setores, conforme demonstra a Tabela 3:

Tabela 3 - Principais setores das MPEs da pesquisa

\begin{tabular}{lcc}
\hline \multicolumn{1}{c}{ Setor } & N & \% \\
\hline Alimentos & 10 & 33,33 \\
Higiene e beleza & 5 & 16,67 \\
Armarinhos & 4 & 13,34 \\
Comércio de Roupas & 2 & 6,67 \\
Comércio de Ração & 2 & 6,67 \\
Móveis/Eletrônicos & 2 & 6,67 \\
Ótica & 1 & 3,33 \\
Automotivo & 1 & 3,33 \\
Papelaria & 1 & 3,33 \\
Farmácia & 1 & 3,33 \\
Caçados & 1 & 3,33 \\
\hline
\end{tabular}

Fonte: resultado da pesquisa, 2016

A maioria das MPEs, segundo a Tabela 3, está atuando há 3 e 4 anos, totalizando $36 \%(n=11)$ da amostra, seguida pelas empresas que atuam entre 5 e 6 anos no mercado com $34 \%(n=10), 27 \%(n=8)$ estão ativas há mais de 7 anos e 3\% $(n=1)$ tem de 1 a 2 anos de funcionamento, a Figura 2 demonstra esses resultados.

Figura 2 - Tempo de atuação das MPEs

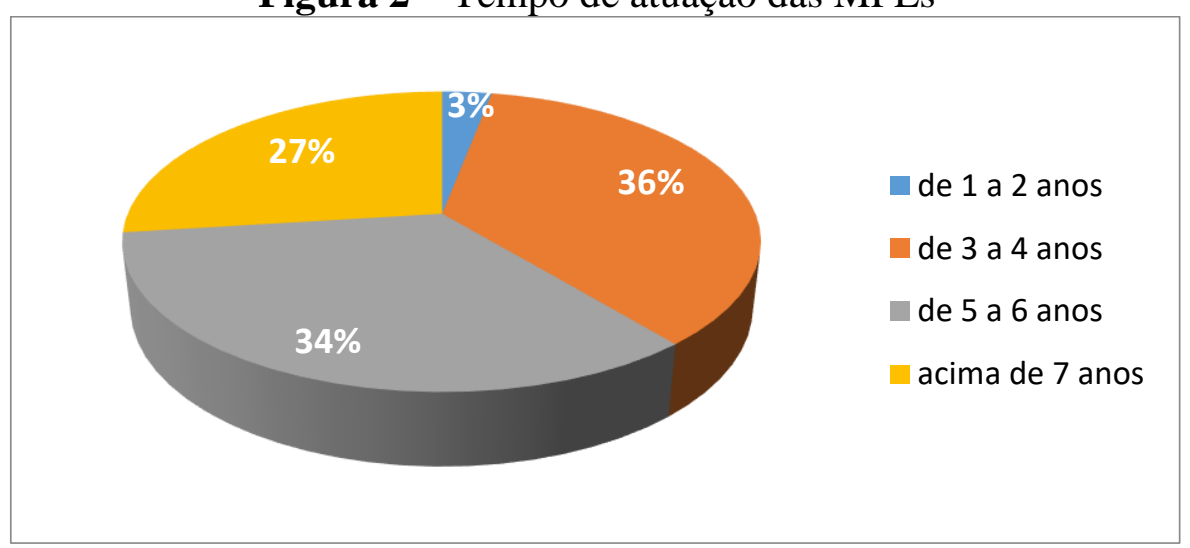

Fonte: elaborado pelos autores, 2016

REMIPE- Revista de Micro e Pequenas Empresas e Empreendedorismo da Fatec Osasco 
Verifica-se, conforme a Figura 2, que as empresas da amostra desta pesquisa fazem parte dos $77 \%$ das MPEs que ultrapassam os dois anos de sobrevivência no mercado competitivo (SEBRAE, 2016). Um dos pontos relevantes que pode justificar a sobrevivência dessas empresas é o grau de conhecimento dos gestores, que devem ser profissionais capacitados e preparados para as constantes alterações nas leis fiscais (VICENTI et al., 2012). Todas as MPEs participantes da pesquisa pertencem ao regime de tributação do SIMPLES e realizam sua contabilidade em Escritórios Especializados.

Vicenti et al. (2012) ressaltam ainda que entre as capacidades dos gestores deve-se configurar a liderança e a preocupação com os investimentos e retornos financeiros da empresa, ou seja, com os resultados que podem afetar diretamente o processo de vantagem competitiva da MPE. O surgimento do SIMPLES colaborou no desenvolvimento e crescimento das empresas optantes, como aponta o estudo desenvolvido por Paes (2014), que sugere ainda que o SIMPLES teve efeito importante sobre a economia nos últimos anos. Entretanto, o autor ressalta que trata-se de sistema que tem um custo muito elevado para a sociedade brasileira, necessitando, portanto, de vigilância por parte das administrações tributárias envolvidas, permitindo que apenas pequenas empresas permaneçam no regime.

Verificou-se que a maioria das empresas $43,33 \%(n=13)$ possui de 1 a 3 funcionários, 36,67\% ( $\mathrm{n}=11)$ possuem de 4 a 6, as MPEs que possuem de 7 a 9 funcionários somaram $13,34 \%(n=4)$ e as que contam com mais de 10 colaboradores são 6,67\% (n=2), conforme Tabela 4. Constata-se que, de acordo com a classificação das MPEs, somente duas empresas se enquadram como Empresa de Pequeno Porte, pois possuem mais de 10 funcionários (SEBRAE, 2013).

Tabela 4 - Quantidade de funcionários das MPEs

\begin{tabular}{lcc}
\hline Quantidade de Funcionários das MPEs & N & \% \\
\hline 1 a 3 & 13 & 43,33 \\
4 a 6 & 11 & 36,66 \\
7 a 9 & 4 & 13,34 \\
10 ou mais & 2 & 6,67 \\
\hline
\end{tabular}

Fonte: resultado da pesquisa, 2016 
No que diz respeito ao grau de informatização das MPEs, $20 \%(\mathrm{n}=6)$ afirmaram que realizam seus controles contábeis por fichas manuscritas, enquanto que $80 \%(n=24)$ relatam realizar esse controle de forma parcialmente informatizada, conforme Figura 3:

Figura 3- Grau de informatização das MPEs

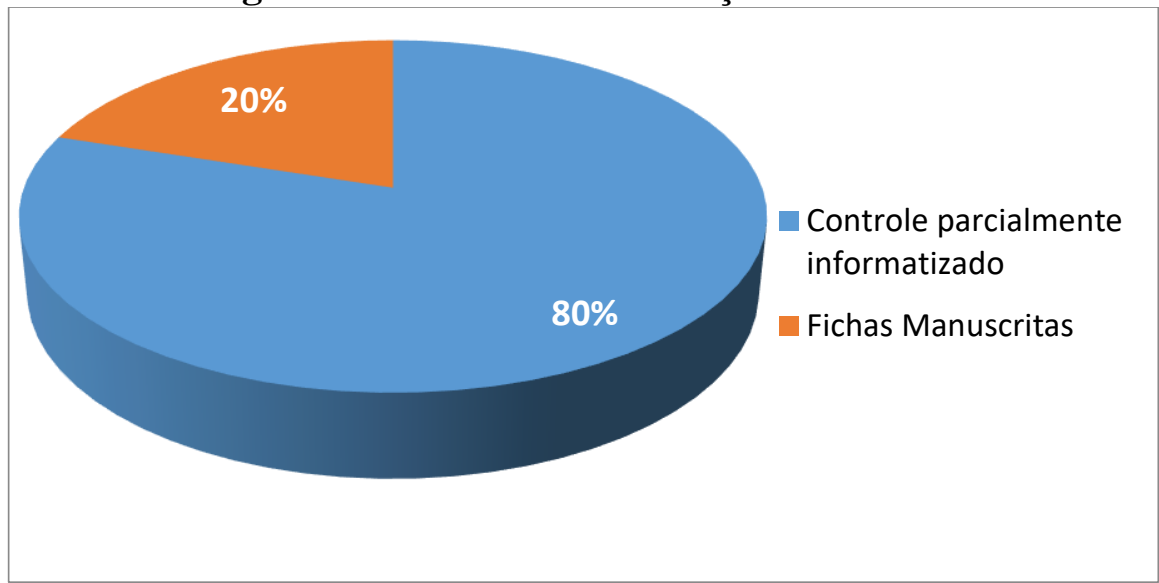

Fonte: elaborado pelos autores, 2016

A sobrevivência das MPEs depende de um conjunto de fatores, entre eles se destaca a tecnologia da informação e comunicação como forma de inovar e manter um diferencial, tornando-a mais competitiva e possibilitando atender os clientes exigentes de um mercado globalizado e altamente competitivo (SILVA e DACORSO, 2013). Para melhor compreensão do número de MPEs que possuem o conhecimento sobre Contabilidade Gerencial e as que fazem uso dessas ferramentas, fez-se necessária a classificação de acordo com o faturamento, proporcionando uma visualização mais abrangente dos resultados da pesquisa, conforme descrito na Tabela 5:

Tabela 5 - Faturamento das MPEs e a utilização da Contabilidade Gerencial

\begin{tabular}{lccc}
\hline & & $\begin{array}{c}\text { MPES que } \\
\text { conhecem CG }\end{array}$ & $\begin{array}{c}\text { MPEs que } \\
\text { utilizam a CG }\end{array}$ \\
\cline { 3 - 4 } Faturamento da MPE & Total & $\mathbf{N}$ & $\mathbf{N}$ \\
\hline Até $\mathrm{R} \$ 30.000,00$ & 7 & 0 & 0 \\
De $\mathrm{R} \$ 30.001,00$ a $\mathrm{R} \$ 50.000,00$ & 10 & 6 & 2 \\
De $\mathrm{R} \$ 50.001,00$ a $\mathrm{R} \$$ & & & 7 \\
100.000,00 & 7 & 7 & 4 \\
Acima de $\mathrm{R} \$ 100.001,00$ & 6 & 5 & \\
\hline
\end{tabular}

Fonte: resultados da pesquisa, 2016

Ao constatar na Tabela 5 que as MPEs com faturamento até R\$ 30.000,00 não conhecem e não utilizam a contabilidade gerencial em suas organizações, entende-se como 
um fator preocupante e que pode resultar nos descontrole contábil e acabar se configurando entre as MPEs que não sobrevivem por falta de gestão adequada.

Entre as empresas, conforme Tabela 5 que faturam de $\mathrm{R} \$ 30.001,00$ a $\mathrm{R} \$ 50.000,00$, 6 delas afirmam conhecer a contabilidade gerencial, porém, somente duas MPEs a utilizam. Nas empresas com faturamento entre $\mathrm{R} \$ 50.001,00$ a $\mathrm{R} \$ 100.000,00$ todas afirmaram conhecer e utilizar a contabilidade gerencial e, das que faturam acima de R $\$ 100.001,00$, apesar de seis 6 delas conhecerem, apenas 4 afirmaram fazer uso da contabilidade geral.

Observa-se nessa classificação da Tabela 5 que, quanto maior o faturamento da MPEs, maior é o seu conhecimento sobre a contabilidade gerencial. Porém, sua utilização não possui a mesma linha do conhecimento, pois, em alguns casos, as empresas somente conhecem, mas não utilizam a ferramenta de gestão. Para essas MPEs a contabilidade é vista apenas como instrumento fiscal e não como importante ferramenta de auxílio para o gerenciamento de uma organização, o que, apesar de ser comum entre as MPEs, trata-se de uma visão equivocada da contabilidade gerencial (VICENTI et al., 2012).

Entre as ferramentas da contabilidade gerencial, o controle de contas a pagar é utilizado por todas as MPEs participantes da pesquisa. Entretanto, constatou-se que apenas 2 $(6,67 \%)$ das empresas utilizam todas as ferramentas da contabilidade gerencial, sendo elas MPEs com faturamento anual acima de R $\$ 100.000,00$.

\section{CONCLUSÃO}

Ao concluir este estudo que teve como objetivo identificar a estrutura contábil entre as microempresas localizadas no bairro do Grajaú no município de São Paulo - SP, pode-se afirmar que as empresas com faturamento de até $\mathrm{R} \$ 30.000,00$ não possuem o conhecimento sobre contabilidade gerencial, e, consequentemente, não fazem uso dessa ferramenta de gestão. O conhecimento sobre a contabilidade gerencial cresce conforme o faturamento da empresa. Entretanto, sua utilização não está relacionada com o conhecimento, visto que, algumas MPEs afirmam conhecer, mas não utilizam a ferramenta na organização.

Diante disso, respondendo à pergunta problema deste estudo, verificou-se que tanto a estrutura contábil quanto a atuação dos profissionais da contabilidade se faz necessário entre os gestores das MPEs do bairro do Grajaú, principalmente entre os que faturam R\$ 30.000,00 anuais, resultando na manutenção da competitividade e, consequentemente, na sua permanência no mercado globalizado (LEE et al., 2010). 
Treinamentos e cursos de capacitação na gestão da informação devem ser desenvolvidos no bairro, visando à conscientização entre os gestores da importância da estrutura contábil para a MPE e o valor de cada informação para a competitividade da organização. Destaca-se ainda a necessidade de investimentos em tecnologia da informação para um gerenciamento eficiente das informações lançadas na contabilidade gerencial, conforme apontado por Andrade (2012).

Entre as limitações deste estudo, destaca-se a resistência na revelação, por parte dos gestores das MPEs, do valor do faturamento anual da empresa, constatando como uma dificuldade inerente ao processo de pesquisa acadêmica na área da contabilidade.

Diante dos resultados obtidos, recomendam-se novos estudos com abordagem voltada ao processo de conhecimento e conscientização da importância da contabilidade gerencial para as empresas com faturamento até 30 mil reais/ano, visando sua permanência no mercado globalizado.

\section{REFERÊNCIAS}

ALMEIDA, D. C.; CASTRO, M. C. S.; ALVES, N. M. S.; PERUZZI, M. H. A. A relevância da contabilidade gerencial na gestão empresarial. Faculdades Integradas de Três Lagoas, 2013, p.1-11.

ANDRADE, R. F. Contexto do empreendedorismo no Brasil. IN: Empreendedorismo inovador: como criar startups de tecnologia no Brasil. São Paulo: Évora, 2012.

AUTRAN, M; COELHO, C. U. F. Básico de Contabilidade e Finanças. Rio de Janeiro: Senac Nacional, 2012.

AZEVEDO, G. Micros e pequenas têm impacto significativo na economia. Jornal do Brasil, set. 2013.

BARRETO, L. Impacto das microempresas na economia. Diário Comércio Indústria e Serviço, maio, 2013.

BRASIL. Lei Complementar 123, de 14 de dezembro de 2006. Institui o Estatuto Nacional da Microempresa e da Empresa de Pequeno Porte. Diário Oficial da União. Brasília, 2006.

CAETANO, B.; BARTOLOMEI, R.; TORTORELLA, R. Conquistas e novos desafios para as Micro Empresas. São Paulo: Ex libris, 2012.

CHING, Y. H.; MARQUES, F. P. L. Contabilidade e Finanças para não especialistas. $3^{\mathrm{a}}$ ed. São Paulo: Pearson Prentice Hall, 2010. 
CONCEIÇÃO, A. M.; SOUZA, P. M. V. A contabilidade gerencial nas micro e pequenas empresas como instrumento de gestão. Revista Eletrônica Faculdade Jose Augusto Vieira. 2013;6(1):1-14.

FNQ - FUNDAÇÃO NACIONAL DA QUALIDADE. Modelo de Excelência de Gestão. 2014. Disponível em: <http://www.fnq.org.br/avalie-se/metodologia-meg/modelo-deexcelencia-da-gestao> Acesso em: 24 set. 2016.

GIL, A. C. Métodos e técnicas de pesquisa social. 6.ed. São Paulo: Atlas, 2012.

IUDÍCIBUS, S. Contabilidade gerencial. 14ª ed. São Paulo: Atlas, 2010.

LEE, S.; PARK, G.; YOON, B.; PARK, J. Open innovation in SMEs: an intermediated network model. 2010. IN: SILVA, G; DACORSO, A. L. R. Inovação aberta como uma vantagem competitiva para a micro e pequena empresa. Revista de Administração e Inovação. São Paulo, v. 10, n. 3, p 251-268, jul/set, 2013.

LUCAS, A. C.; PARENTE, T. C.; AMORIM, W. A. C.; FICHER, A. L. Escassez de Mão de Obra: Dimensionamento e Características em Empresas no Brasil. IV Encontro de gestão de pessoas e relações de trabalho. Brasília, 2013.

MARTINS, J. Excelência da gestão: o desafio das MPEs. Revista PEGN [on-line] jun. 2013. Disponível em: <http://revistapegn.globo.com/Colunistas/Jairo-

Martins/noticia/2013/06/excelencia-da-gestao-o-desafio-das-mpes.html> Acesso em: 13 out. 2016.

MARTINS, P. G.; CAMPOS, P. R. Administração de Materiais e Logística. São Paulo: Saraiva, 2010.

PAES, N. L. Simples Nacional no Brasil: o difícil balanço entre estímulos às pequenas empresas e aos gastos tributários. Nova economia. 2014;24(3):541-554.

SEBRAE. Controle de conta a receber. 2016. Disponível em:

<http://www.sebrae.com.br/sites/PortalSebrae/ufs/ap/artigos/controle-de-contas-areceber,cb84164ce51b9410VgnVCM1000003b74010aRCRD> Acesso em: 11 set. 2016.

SEBRAE. Critérios de Classificação de Empresas: EI - ME - EPP. 2013. Disponível em: <http://www.sebrae-sc.com.br/leis/default.asp?vcdtexto=4154> Acesso em: 15 ago. 2016.

SEBRAE. Sobrevivência das Empresas no Brasil. Coleção Estudos e Pesquisas. Junho, 2013. Disponível em:

<http://www.sebrae.com.br/Sebrae/Portal\%20Sebrae/Anexos/Sobrevivencia_das_empresas_ no_Brasil=2013.pdf> Acesso em: 15 ago. 2016.

SILVA, E. H. D. R.; LIMA, E. P.; COSTA, S. E. G.; SANT’ANNA, A. M. O. Análise comparativa de rentabilidade: um estudo sobre o Índice de Sustentabilidade Empresarial. Revista Gestão e Produção São Carlos. 2015;22(4):743-754. Disponível em: < http://www.scielo.br/pdf/gp/2015nahead/0104-530X-gp-0104-530X1889-14.pdf> Acesso em: 24 set. 2016. 
SILVA, G; DACORSO, A. L. R. Inovação aberta como uma vantagem competitiva para a micro e pequena empresa. Revista de Administração e Inovação. São Paulo, v. 10, n. 3, p 251-268, jul/set, 2013.

VICENTI, A. R. N.; LEITE, E. B.; ALBERTI, X, R.; POLIZER, B. L. A utilização da contabilidade nas micro e pequenas empresas como fator determinante na sua gestão no município de Alta Floresta - MT. Revista Eletrônica ReFAF, v. 1, n. 1, 2012. 